On 15th July 1974 the Ministry for Greenland invited applications for petroleum concessions within three areas offshore West Greenland (fig. 4). On the closing date of 15 th October 22 companies had responded to the invitation, which is a firm indication of continuing interest in the potential of this area. GGU has assisted the Ministry in assessing the concession applications received.

Although interest has been concentrated on West Greenland, in particular the West Greenland shelf, other areas have also attracted attention. Until late 1973 three companies held prospecting licences for petroleum on land in North Greenland. One of these undertook extensive airborne magnetometer surveys, aerial photography and field work. Numerous oil companies have expressed interest in the sedimentary basin of central East Greenland and the continental shelf off East Greenland. One mining company holds an exclusive concession over the sedimentary area on land in this area. The concession includes petroleum rights. No licences or concessions have yet been granted over the East Greenland shelf.

The Survey is represented in the working group drawing up regulations to govern the activities of companies undertaking mineral exploration on land in Greenland and in adjacent marine areas. In this connection the writer has participated in discussions with the Norwegian Petroleum Directorate in Stavanger, the Department of Indian and Northern Affairs in Ottawa and the Department of Energy, Mines and Resources in Ottawa.

\title{
References
}

Henderson, G. 1969: Oil and gas prospects in the Cretaceous-Tertiary basin of West Greenland. Rapp. Grønlands geol. Unders. 22, $63 \mathrm{pp}$.

Hood, P. J., Sawatzky, P. \& Bower, M. E. 1967: Progress report on low-level aeromagnetic profiles over the Labrador Sea, Baffin Bay, and across the North Atlantic Ocean. Pap. Geol. Surv. Can. 66-58, 11 pp.

Rosenkrantz, A. \& Pulvertaft, T. C. R. 1969: Cretaceous-Tertiary stratigraphy and tectonics in northern West Greenland. Mem. Amer. Ass. Petrol. Geol. 12, 883-898.

\section{X-ray fluorescence spectrometry at GGU}

\section{Ib Sørensen}

In 1971 GGU started to establish a modern laboratory for rock analysis based on X-ray fluorescence spectrometry and a manual Siemens SRS sequence spectrometer, prepared for automation, was bought. It is difficult to imagine a modern X-ray spectrometer without automatic preselection of measuring parameters but the automation can be present in varying degrees and can follow different paths. For various reasons GGU chose an on-line computer control connected via interface to a Digital PDP-8E mini-computer. By this selection we have obtained an almost fully automatic instrument which has so far proved to be excellent both in terms of measuring accuracy and technical reliability.

The so-called LINQUA programme chooses the detector, collimator, crystal, gonio- 
meter setting and length of measuring time, changes between two samples and calculates the concentration of a given element from the measured X-ray intensity. Measurements can be made separately or in a fixed sequence. Finally, the programme writes out the results of the measurements via a teletype. The operator communicates with the programme via the same teletype but when the starting signal for a measuring sequence is given, everything proceeds automatically. A measuring sequence for the usual rock forming elements can be carried through in 35 minutes for two samples.

A great advantage of the computer control is that it is easy to change from one type of measurement to another, e.g. from rock analyses to ore analyses. However, this does not mean that it is practical to do so from day to day since a new and untested measuring programme will always demand a great deal of programming and calibration work. In addition, different measuring programmes rarely make the same demands on the X-ray tubes and remaining measuring parameters, including sample preparation.

The method of sample preparation employed is very important for obtaining analytical results of good precision and accuracy. The sample presented for the X-ray spectrometer must be a perfect plane, homogeneous and free from mineralogcial and grain size effects. For several reasons we have selected a sample preparation method developed by the Geochemical Department, University of Leeds (Padfield \& Gray, 1971). The rock powder is fused to a borate glass with sodium tetraborate in the ratio 1:7. The preparation method makes $\mathrm{Na}$ determination impossible, but this is not a serious limitation since lack of instrumental sensitivity for the softest X-ray region makes $\mathrm{Na}$ as well as $\mathrm{Mg}$ determinations very difficult. We have found it preferable to measure these two elements by atomic absorption.

By careful weighing and fusion to complete homogeneity, it is possible to obtain a total analytical standard deviation almost only determined by the counting statistics and not by the sample preparation. However, it is our experience that it is necessary to keep the crucible in continous movement during fusion, and that a longer fusion time than employed at Leeds is required.

In order to make the XRF measurements independent of long term drifts it is common practice to form the quantity $R=I / I_{\mathrm{s}}$ and to plot $R$ versus $C$, instead of $C$ against $l$, in a concentration curve. $I_{\mathrm{s}}$ is the measurement on a reference standard carried out immediately to the unknown and under the same conditions in every sense. However, this method is not used by the Siemens SRS instrument under control of the LINQUA programme. Instead, the measured intensity, $I$, is directly converted to a concentration, $C_{E}$, using the equation:

$$
C_{\mathrm{E}}=A+B \cdot I+C \cdot I^{2}
$$

( $A, B$ and $C$ are calibration constants, $C=\mathrm{O}$ in case of a linear calibration curve).

This calculation method calls for an unusually high degree of instrumental long term stability, which must be better than $0.1 \%$. It is our experience that this is easily obtained when the instrument is in good working order, when the room temperature is constant and when the $\mathrm{kV} / \mathrm{mA}$ setting for the X-ray tube is never changed. In return, this method needs only half the measuring time of the ratio method. It goes 
without saying, that serious problems will arise from long term drift due to instrumental instability.

Matrix effects, the influence of an element $j$ on the measured XRF intensity $I_{i}$ from an element $i$, have often been a great problem in XRF analysis. Several approaches to the question exist in the literature. However, much confusion is present since effects of improper sample preparation, or even-line coincidence, have been misinterpretated as matrix effects.

If standards and unknowns match perfectly, matrix effects are not present. The greater the difference between the two, the more necessary it will be to make matrix corrections. However, all other possible influences must be carefully eliminated before disagreements are interpreted as matrix effects. For matrix correction we use the Siemens MATKOR programme (Thiele, 1971) which is an overlay to the LINQUA programme. This theoretical correction model is universal in its application and not restricted to use in XRF analysis. The fundamental view is that the true concentration $C_{i}$ can be derived from the apparent concentration $C_{\mathrm{E}, i}$ as a result of multiplication by a calculated correction factor (nearly 1) consisting of contributions from all the interfering elements, according to their concentrations, for example:

$$
C_{i}=C_{\mathrm{E}, i} \cdot\left(K_{0}+K_{1} \cdot C_{1}+K_{2} \cdot C_{2} \ldots+K_{j} \cdot C_{j}\right)
$$

If the constants $K_{\mathrm{n}}$ are determined experimentally, for example by measuring synthetic standards based on pure oxides, the matrix correction will be independent of theoretical considerations and only dependent on the instrument used.

Constants for matrix correction of $\mathrm{Si}, \mathrm{Fe}$ and $\mathrm{Al}$ are available at this time and the results obtained seem very promising.

With the described instrumentation we feel that GGU is well equipped to cope with the increasing demand for analyses. The projected capacity per year of the system is 2000 analyses of high precision, and with an accuracy of, for example, $0.2 \%$ for $\mathrm{SiO}_{2}$ determinations.

Although the number of analyses carried out in 1974 approached 2000, only a quarter of this number were new analyses. The remaining determinations have been control runs on samples of known composition after periods of inoperation. Of this we have had a rather high number in connection with the repair or exchange of faulty/defective components in the spectrometer. Semi-conductors and switch transistors were introduced into electronic engineering several years ago but, unfortunately, electro-mechanical relays and mechanical micro-switches still exist in modern instruments. In contrast there have been no errors in the computer or the interface.

\section{References}

Padfield, T. \& Gray, A. 1971: Major element rock analysis by X-ray fluorenscence - a simple fusion method. Philips Bulletin analytical equipment. 4 pp.

Thiele, B. 1971: Determination of the concentration in multi-substance systems by means of X-ray fluorescence analysis. Siemens Rev. 38, 3-12. 